\title{
Keratinocyte expression of inflammatory mediators plays a crucial role in substance P-induced acute and chronic pain
}

\author{
Tzuping Wei ${ }^{1}$, Tian-Zhi Guo ${ }^{1}$, Wen-Wu Li ${ }^{1,2,3}$, Saiyun Hou' ${ }^{1}$, Wade S Kingery ${ }^{1}$ and John David Clark ${ }^{2,3^{*}}$
}

\begin{abstract}
Tibia fracture in rats followed by cast immobilization leads to nociceptive, trophic, vascular and bone-related changes similar to those seen in Complex Regional Pain Syndrome (CRPS). Substance P (SP) mediated neurogenic inflammation may be responsible for some of the signs of CRPS in humans. We therefore hypothesized that SP acting through the SP receptor (NK1) leads to the CRPS-like changes found in the rat model. In the present study, we intradermally injected rats with SP and monitored hindpaw mechanical allodynia, temperature, and thickness as well as tissue levels of tumor necrosis factor-a (TNF-a), interleukin $1 \beta(\mathrm{IL}-1 \beta)$, interleukin 6 (IL-6), and nerve growth factor- $\beta$ (NGF) for $72 \mathrm{~h}$. Anti-NGF antibody was utilized to block the effects of SP-induced NGF up-regulation. Fracture rats treated with the selective NK1 receptor antagonist LY303870 prior to cast removal were assessed for BrdU, a DNA synthesis marker, incorporation in skin cells to examine cellular proliferation. Bone microarchitecture was measured using micro computed tomography $(\mu \mathrm{CT})$. We observed that: (1) SP intraplantar injection induced mechanical allodynia, warmth and edema as well as the expression of nociceptive mediators in the hindpaw skin of normal rats, (2) LY303870 administered intraperitoneally after fracture attenuated allodynia, hindpaw unweighting, warmth, and edema, as well as cytokine and NGF expression, (3) LY303870 blocked fracture-induced epidermal thickening and BrdU incorporation after fracture, (4) anti-NGF antibody blocked SP-induced allodynia but not warmth or edema, and (5) LY303870 had no effect on bone microarchitecture. Collectively our data indicate that SP acting through NK1 receptors supports the nociceptive and vascular components of CRPS, but not the bone-related changes.
\end{abstract}

\section{Introduction}

Complex regional pain syndrome (CRPS) is a painful, disabling and often chronic condition affecting the extremities and is a frequent sequela of tibial and radial fractures [1]. Previously we described a distal tibial fracture model in rats that exhibits chronic unilateral hindlimb warmth, edema, facilitated spontaneous protein extravasation, allodynia, postural unweighting, and periarticular osteoporosis [2]. These post-fracture changes closely resemble the clinical presentation of patients with acute CRPS.

\footnotetext{
* Correspondence: djclark@stanford.edu

${ }^{2}$ Anesthesiology Service, Veterans Affairs Palo Alto Health Care System, 3801

Miranda Avenue (112-A), Palo Alto, CA94304, USA

${ }^{3}$ Department of Anesthesiolgy, Stanford University School of Medicine,

Stanford CA94304, USA

Full list of author information is available at the end of the article
}

The inflamed appearance of the limb affected by CRPS has led to the hypothesis that the local production of inflammatory mediators might be involved in the etiology of the condition. There is increased TNF- $\alpha$ and IL- 6 in blister fluid from patients with early CRPS [3]. Similarly, we have observed a dramatic increase in hindpaw skin expression of TNF- $\alpha$, IL- $1 \beta$, IL- 6 , and nerve growth factor (NGF) at both the mRNA and protein levels [4-6] in the rat fracture model. Treating fractured rats with a TNF- $\alpha$ inhibitor (etanercept), an IL-1 receptor antagonist (anakinra), or an anti-NGF antibody (tanezumab) reduced hindpaw allodynia and unweighting at 4 weeks post-fracture $[4,5,7]$. These data indicate that fractureinduced allodynia can be attributed partially to local inflammatory mediators because all these drugs are large molecular weight proteins that cannot cross the blood brain barrier. Recently we identified keratinocytes in the

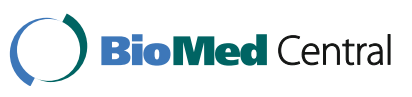


fracture-affected dorsal hindpaw as the primary cellular source of the inflammatory nociceptive mediators TNF- $\alpha$, IL- $1 \beta$, IL- 6 , and NGF in the rat fracture CRPS model [8].

Several lines of clinical investigation support the hypothesis that facilitated peripheral neurogenic inflammation, involving neuropeptides such as substance P (SP), contributes to some of the signs and symptoms of CRPS [9-12]. When SP is microdialyzed in the skin of normal volunteers and patients with CRPS, much greater protein extravasation is observed in CRPS-affected limbs, indicating post-junctional facilitation of the SP extravasation response $[11,13]$. Furthermore, tibial fracture in rats upregulates NK1 receptor expression in skin (keratinocytes) and microvasculature (endothelial cells) of the affected hindpaw [14], and SP signaling is enhanced in the injured limb of these animals $[2,14,15]$. Treatment with the selective NK1 antagonist LY303870 attenuated spontaneous protein extravasation, edema, warmth, and allodynia in the hindpaw after fracture [2]. SP can induce keratinocyte proliferation and activation in vitro $[16,17]$, and in rats electrical stimulation of the sciatic nerve at intensities causing neuropeptide release leads to a gradual increase in hindpaw skin levels of TNF- $\alpha$, IL-1 $\beta$, IL-6, and NGF [18]. When SP or calcitonin gene-related peptide (CGRP) was microdialyzed in the skin of normal volunteers there was no immediate pain response [13]. These data support the premise that SP and CGRP act as intermediate mediators in the development of inflammatory pain via other downstream substances such as cytokines and NGF.

In light of these observations, we hypothesized that: 1) exogenous SP signaling in the skin can sequentially upregulate the expression of TNF- $\alpha$, IL- $1 \beta$, IL- 6 , and NGF, resulting in hindpaw nociceptor sensitization, allodynia and unweighting; 2) NGF is the final downstream inflammatory mediator for SP-induced cutaneous nociceptive sensitization; 3) endogenous SP signaling in the fractured limb activates keratinocytes and upregulates expression of TNF- $\alpha$, IL- $1 \beta$, IL- 6 , and NGF, resulting in hindpaw nociceptor sensitization, allodynia and unweighting, and 4) SP signaling after fracture induces periarticular bone loss. The experiments described in this study were designed to test these hypotheses.

\section{Materials and methods}

These experiments were approved by our institute's Subcommittee on Animal Studies and followed the guidelines of the International Association for the Study of Pain (IASP) [19]. Adult (9-month-old) male Sprague Dawley rats (Simonsen Laboratories, Gilroy, CA, USA) were used in all experiments. The animals were housed individually in isolator cages with solid floors covered with $3 \mathrm{~cm}$ of soft bedding and were fed and watered ad libitum. During the experimental period the animals were fed Lab Diet 5012 (PMI Nutrition Institute, Richmond, IN, USA), which contained $1.0 \%$ calcium, $0.5 \%$ phosphorus, and $3.3 \mathrm{IU} / \mathrm{g}$ of vitamin D3, and were kept under standard conditions with a 12-h light-dark cycle.

\section{Surgery}

Tibial fracture was performed under isoflurane anesthesia as we have previously described [2]. The right hindlimb was wrapped in stockinet $(2.5 \mathrm{~cm}$ wide) and the distal tibia was fractured using pliers with an adjustable stop that had been modified with a 3-point jaw. The hindlimb was wrapped in casting tape so the hip, knee and ankle were flexed. The cast extended from the metatarsals of the hindpaw up to a spica formed around the abdomen. To prevent the animals from chewing at their casts, the cast material was wrapped in galvanized wire mesh. The rats were given subcutaneous saline and buprenorphine $(0.03 \mathrm{mg} / \mathrm{kg})$ immediately after the procedure and on the next day after fracture for postoperative hydration and analgesia. At 4 weeks the rats were anesthetized with isoflurane and the cast removed with a vibrating cast saw. All rats used in this study had union at the fracture site after 4 weeks of casting.

\section{Drugs}

The anti-NGF antibody muMab 911 (Rinat Laboratories, Pfizer Inc, SF, CA, USA) is a TrkA immunoglobulin G (TrkA-IGG) fusion molecule that binds to the NGF molecule, thus blocking the binding of NGF to the TrkA and p75 NGF receptors and inhibiting TrkA autophosphorylation [20]. Pharmacokinetic and behavioral experiments in rodents indicate that muMab 911 has a terminal half-life of 5 to 6 days in plasma and that a $10 \mathrm{mg} / \mathrm{kg}$ dose administered every 5 or 6 days reduces nociceptive behavior in a variety of rodent chronic pain models [21-23].

The NK1 receptor antagonist LY303870 was a generous gift from Dr. L. Phebus (Eli Lily Company, Indianapolis, IN, USA). This compound has nanomolar affinity for the rat NK1 receptor, has no affinity for 65 other receptors and ion channels, has no sedative, cardiovascular or core body temperature effects in rats at systemic doses up to $30 \mathrm{mg} / \mathrm{kg}$, and is physiologically active for $24 \mathrm{~h}$ after a single systemic dose of $10 \mathrm{mg} / \mathrm{kg}$ [24-26].

\section{Hindpaw nociception}

To measure mechanical allodynia in the rats an updown von Frey testing paradigm was used as we have previously described [2,15,27]. Rats were placed in a clear plastic cylinder $(20 \mathrm{~cm}$ in diameter $)$ with a wire mesh bottom and allowed to acclimate for 15 minutes. The paw was tested with one of a series of eight von 
Frey hairs ranging in stiffness from $0.41 \mathrm{~g}$ to $15.14 \mathrm{~g}$. The von Frey hair was applied against the hindpaw plantar skin at approximately midsole, taking care to avoid the tori pads. The fiber was pushed until it slightly bowed and then it was jiggled in that position for $6 \mathrm{sec}-$ onds. Stimuli were presented at an interval of several seconds. Hindpaw withdrawal from the fiber was considered a positive response. The initial fiber presentation was $2.1 \mathrm{~g}$ and the fibers were presented according to the up-down method of Dixon to generate six responses in the immediate vicinity of the $50 \%$ threshold. Stimuli were presented at an interval of several seconds. An incapacitance device (IITC Inc. Life Science, Woodland, CA, USA) was used to measure hindpaw unweighting. The rats were manually held in a vertical position over the apparatus with the hindpaws resting on separate metal scale plates and the entire weight of the rat was supported on the hindpaws. The duration of each measurement was $6 \mathrm{~s}$ and 10 consecutive measurements were taken at 60 -second intervals. Eight readings (excluding the highest and lowest ones) were averaged to calculate the bilateral hindpaw weight-bearing values.

\section{Hindpaw temperature}

The room temperature was maintained at $23^{\circ} \mathrm{C}$ and humidity ranged between 25 and $45 \%$. The temperature of the hindpaw was measured using a fine wire thermocouple (Omega, Stanford, CT, USA) applied to the paw skin, as previously described $[2,15,27]$. The investigator held the thermistor wire using an insulating Styrofoam block. Three sites were tested over the dorsum of the hindpaw; the space between the first and second metatarsals (medial), the second and third metatarsals (central), and the fourth and fifth metatarsals (lateral). After a site was tested in one hindpaw the same site was immediately tested in the contralateral hindpaw. The testing protocol was medial dorsum right then left, central dorsum right then left, lateral dorsum right then left, medial dorsum left then right, central dorsum left then right, and lateral dorsum left then right. The six measurements for each hindpaw were averaged for the mean temperature.

\section{Hindpaw thickness}

A laser sensor technique was used to determine the dorsal-ventral thickness of the hindpaw, as we have previously described [15]. Before baseline testing the bilateral hindpaws were tattooed with a 2 to $3 \mathrm{~mm}$ spot on the dorsal skin over the midpoint of the third metatarsal. For laser measurements each rat was briefly anesthetized with isoflurane and then held vertically so the hindpaw rested on a table top below the laser. The paw was gently held flat on the table with a small metal rod applied to the top of the ankle joint. Using optical triangulation, a laser with a distance measuring sensor was used to determine the distance to the table top and to the top of the hindpaw at the tattoo site and the difference was used to calculate the dorsal-ventral paw thickness. The measurement sensor device used in these experiments (4381 Precicura, Limab, Goteborg, Sweden) has a measurement range of $200 \mathrm{~mm}$ with a $0.01 \mathrm{~mm}$ resolution.

\section{Homogenization procedure and enzyme immunoassay for TNF- $a$, IL-1 $\beta$, IL- 6 and NGF}

Rat hindpaw dorsal skin was collected after behavioral testing or at time points as indicated and frozen immediately on dry ice. Skin tissue was cut into fine pieces in ice-cold phosphate buffered saline (PBS), $\mathrm{pH}$ 7.4, containing protease inhibitors (aprotinin $(2 \mu \mathrm{g} / \mathrm{ml}$ ), leupeptin $(5 \mu \mathrm{g} / \mathrm{ml})$, pepstatin $(0.7 \mu \mathrm{g} / \mathrm{ml})$, and PMSF $(100 \mu \mathrm{g} / \mathrm{ml})$; Sigma, St. Louis, MO, USA) followed by homogenization using a rotor/stator homogenizer. Homogenates were centrifuged for 5 minutes at $14,000 \mathrm{~g}$, and at $4^{\circ} \mathrm{C}$. Supernatants were transferred to fresh precooled Eppendorf tubes. Triton X-100 (Boehringer Mannheim, Germany) was added at a final concentration $0.01 \%$. The samples were centrifuged again for 5 minutes at $14,000 \mathrm{~g}$ at $4^{\circ} \mathrm{C}$. The supernatants were aliquoted and stored at $-80^{\circ} \mathrm{C}$. TNF- $\alpha$, IL- $1 \beta$, and IL- 6 protein levels were determined using EIA kits (R\&D Systems, Minneapolis, MN, USA). The NGF concentrations were determined using the NGF Emax ${ }^{\circledR}$ ImmunoAssay System kit (Promega, Madison, WI, USA) according to the manufacturer's instructions. The optical density (OD) of the reaction product was read on a microplate reader at $450 \mathrm{~nm}$. The concentrations of TNF- $\alpha$, IL- $1 \beta$, IL- 6 , and NGF proteins were calculated from the standard curve at each assay. Positive and negative controls were included in each assay. Each protein concentration was expressed as $\mathrm{pg} / \mathrm{mg}$ total protein. Total protein contents in all tissue extracts were measured by the Coomassie Blue Protein Assay Kit (Pierce, Rockford, IL, USA).

\section{Tissue processing and keratinocyte immunofluorescence confocal microscopy}

Animals were euthanized and immediately perfused with

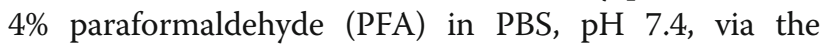
ascending aorta; the hindpaw skin including sub-dermal layers was removed and post-fixed in 4\% PFA for $2 \mathrm{~h}$, and then the tissues were treated with $30 \%$ sucrose in PBS at $4^{\circ} \mathrm{C}$ before embedding in the optimal cutting temperature compound (OCT) (Sakura Finetek USA, Inc., Torrance, California, USA). Following embedding, 10- $\mu \mathrm{m}$ thick slices were made using a cryostat, mounted onto Superfrost microscope slides (Fisher Scientific, Pittsburgh, PA, USA), and stored at $-80^{\circ} \mathrm{C}$.

To examine the effects of intraplantar SP on inflammatory mediator production and NK1 receptor expression 
in epidermal keratinocytes, double immunolabeling was performed as previously described [8]. Briefly, frozen skin sections were permeabilized and blocked with PBS containing $10 \%$ donkey serum and $0.3 \%$ Triton X-100, followed by exposure to the primary antibodies overnight at $4^{\circ} \mathrm{C}$ in PBS containing $2 \%$ serum. Upon detection of the first antigen, a primary antibody from a different species against the second antigen was applied to the sections and visualized using an alternative fluorophoreconjugated secondary antibody. Sections were then rinsed in PBS and incubated with fluorophoreconjugated secondary antibodies against the immunoglobulin of the species from which the primary antibody was generated. After three washes, the sections were mounted with anti-fade mounting medium (Invitrogen, Grand Island, NY, USA). With regard to primary antibodies, goat anti-rat IL-1 $\beta$ (R\&D Systems, 1:200), goat anti-rat NGF- $\beta$ (R\&D Systems, 1:100), rabbit anti-rat NK1 receptor (Sigma-Aldrich, diluted 1:8000) and monoclonal mouse anti-rat keratin (clone AE1/AE3) (Thermo Fisher Scientific, Waltham, MA 02454, USA, diluted 1:50) were used. Double-labeling immunofluorescence was performed with a series of conjugated secondary antibodies (Jackson ImmunoResearch Laboratories), that is, donkey anti-mouse IgG (1:500) conjugated with fluorescein isothiocyanate (FITC) and donkey anti-goat IgG (1:500) conjugated with cyanine dye $3(\mathrm{Cy} 3)$ for coimmunostaining of keratin and IL-1 $\beta$ or NGF, and donkey anti-mouse IgG (1:500) conjugated with $\mathrm{Cy} 3$ and donkey anti-rabbit IgG (1:500) conjugated with FITC for co-staining of keratin and NK1 receptor, respectively.

To assess LY303870 effects on epidermal thickness at 4 weeks post-fracture, the sections of hindpaw skin were permeabilized and blocked as described above, followed by exposure to monoclonal anti-rat keratin (clone AE1/AE3) (Thermo Fisher Scientific, diluted 1:50) overnight at $4^{\circ} \mathrm{C}$ in $\mathrm{PBS}$ containing $2 \%$ serum. The primary antibody was detected using FITC-conjugated donkey anti-mouse IgG $(\mathrm{H}+\mathrm{C})$ antibody (Jackson Immuno Reasearch Laboratories, West Grove, PA, USA, diluted 1:500). Images were obtained using confocal microscopy (Zeiss LSM/510 Upright 2 photon; Carl Zeiss, Thornwood, NY, USA) and stored on digital media. Control experiments included incubation of slices in primary and secondary antibody-free solutions both of which led to low intensity non-specific staining patterns in preliminary experiments (data not shown).

\section{In vivo bromodeoxyuridine (BrdU) labeling and $\mathrm{BrdU}$ immunohistochemistry}

Labeling with BrdU was done to evaluate keratinocyte proliferation. At 3 weeks after tibial fracture, animals were injected intraperitoneally (i.p.) once daily with $50 \mathrm{mg} / \mathrm{kg}$ BrdU (Sigma-Aldrich) for 8 days [28]. Hindpaw skin was harvested and fixed one day after the last injection and processed for immunostaining. Skin sections were pretreated in $2 \mathrm{~N} \mathrm{HCl}$ for 30 minutes at $37^{\circ} \mathrm{C}$, followed by neutralization in $0.1 \mathrm{M}$ borate buffer $(\mathrm{pH} 8.5)$ for 10 minutes and blocking with 10\% normal donkey serum for $1 \mathrm{~h}$ at room temperature, after which immunohistochemistry was performed using a rat anti-BrdU monoclonal antibody (1:300, Accurate Chemical, WESTBURY, NY, USA) and donkey anti-rat fluorescein isothiocyanate secondary antibody (1:400, Jackson Immuno Research Laboratories). After three rinses with PBS, the sections were immunostained with the monoclonal anti-rat keratin as mentioned above. BrdU immunostaining was observed using a Leica DM 2000 fluorescent microscope and imaged using a Spot Camera (version 4.0.8, Diagnostic Instruments, Sterling Heights, MI, USA). The number of BrdU-positive cells was counted, specifically those in keratin-positive cells in the area of the epidermis with a minimum of six sections per animal from seven intact and five fractured animals. Cell densities were calculated by dividing cell numbers by the area. Representative images were obtained using confocal microscopy (Zeiss LSM/510 Upright 2 photon; Carl Zeiss).

\section{Microcomputed tomography $(\mu \mathrm{CT})$}

Ex vivo scanning was performed for assessment of trabecular and cortical bone architecture using micro computer tomography $(\mu \mathrm{CT})$ (VivaCT 40, Scanco Medical AG, Basserdorf, Switzerland). Specifically, trabecular bone architecture was evaluated at the distal femur and cortical bone morphology was evaluated at the midshaft femur. CT images were reconstructed in $1024 \times 1024$ pixel matrices for distal femur and mid-femur samples and stored in 3-dimensional arrays. The resulting grayscale images were segmented using a constrained Gaussian filter to remove noise, and a fixed threshold $(25.5 \%$ of the maximal grayscale value for the vertebrae and the distal femur, and 35\% for the mid-femoral cortical bone) was used to extract the structure of the mineralized tissue. The $\mu \mathrm{CT}$ parameters were set at threshold $=255$, $\sigma=0.8$, support $=1$ for vertebral samples, threshold $=$ $255, \sigma=0.8$, support $=1$ for distal femur, and threshold $=$ $350, \sigma=1.2$, and support $=2$ for mid-femur evaluation analysis. A single operator outlined the trabecular bone region within the distal femur, the vertebral body and the cortical bone region in the mid-femoral shaft. The trabecular bone region was manually identified and all slices containing trabecular bone between the growth plates were included for analysis. In the distal femur 150 transverse slices of $21 \mu \mathrm{m}$ thickness $(21-\mu \mathrm{m}$ isotropic voxel size) encompassing a length of $3.15 \mathrm{~mm}$ were acquired, but only 100 slices encompassing $2.1 \mathrm{~mm}$ of the distal femur were evaluated, starting where the growth 
plate bridge across the middle of the metaphysis ends. The region of interest (ROI) was manually outlined on each CT slice, extending proximally from the growth plate. The bone parameters analyzed included the bone volume fraction (BV/TV) (\%), trabecular number (TbN) $\left(\mathrm{mm}^{-1}\right)$, trabecular thickness (TbTh) $(\mu \mathrm{m})$, trabecular separation $(\mathrm{TbSp})(\mu \mathrm{m})$, and connectivity density (ConnD) $\left(1 / \mathrm{mm}^{3}\right)$. At the femoral mid-shaft, 10 transverse CT slices were obtained, each $21 \mu \mathrm{m}$ thick totaling $0.21 \mathrm{~mm}$ in length $(21 \mu \mathrm{m}$ isotropic voxel size) and these were used to compute the cortical bone area $(\mathrm{Bar})\left(\mathrm{mm}^{2}\right)$, total cross sectional area (TtAr) $\left(\mathrm{mm}^{2}\right)$, medullary area $(\mathrm{MeAr})\left(\mathrm{mm}^{2}\right)$, cortical thickness $(\mathrm{CtTh})(\mu \mathrm{m})$, bone perimeter $(\mathrm{BPm})(\mathrm{mm})$, and relative cortical bone area (BAr/TtAr) (\%).

\section{Study design}

To determine the time course of SP-induced pain behavior and signs of inflammation, normal rats received hindpaw intraplantar injection of $\operatorname{SP}(0,10,25$, and $60 \mu \mathrm{g}$ ) in $50 \mu \mathrm{l}$ of $0.9 \%$ saline. Baseline determinations were made of bilateral hindpaw mechanical nociceptive withdrawal thresholds to von Frey fibers, hindpaw temperature, and hindpaw thickness, and then the rats were injected and retested for behavior at $0.5,1,3,6,24,48$, and $72 \mathrm{~h}$ after SP injection ( $\mathrm{n}=6$ per cohort). Based on the results of this behavioral study, a $25 \mu \mathrm{g}$ dose of SP was selected for evaluating the time course of SPinduced inflammatory mediator expression. After normal rats underwent intraplantar injection with $25 \mu \mathrm{g}$ SP in $50 \mu \mathrm{l}$ of $0.9 \%$ saline, the hindpaw skin was collected at $0,1,3,6,24$, and $48 \mathrm{~h}$ after injection for TNF- $\alpha$, IL- $1 \beta$, IL-6, and NGF protein level determination by EIA $(n=8$ per cohort).

The effects of SP $(25 \mu \mathrm{g})$ intraplantar injection on keratinocyte inflammatory mediator and NK1 receptor expression were evaluated by immunofluorescence confocal microscopy. Normal rats received hindpaw intraplantar injections with $25 \mu \mathrm{g} \mathrm{SP}$, and then the injected hindpaw skin was collected at $0,1,3$, and $6 \mathrm{~h}$ postinjection for immunostaining with anti-IL-1 $\beta$, NGF, or NK1 primary antibody.

To evaluate the contribution of NGF signaling in SP-evoked allodynia, the NGF inhibitor muMab 911 $(10 \mathrm{mg} / \mathrm{kg})$ or vehicle was administered via i.p. injection in normal rats. Three days later, baseline hindpaw von Frey thresholds, temperature, and paw thickness were determined, and then the rats received an intraplantar injection with $25 \mu \mathrm{g}$ SP. At 0.5, 1, 3, 6, 24, 48, and $72 \mathrm{~h}$ post-injection the animals underwent repeat tests.

To test the hypothesis that local SP signaling induces hindpaw pain and inflammation in the CRPS tibial fracture model, fracture rats were treated with either a systemic or locally administered NK1 receptor antagonist
(LY303870). The rats were divided into four cohorts ( $\mathrm{n}=8$ to 16 rats per cohort). Three cohorts underwent right distal tibial fracture with hindlimb cast immobilization for 4 weeks. The day after cast removal, all rats underwent bilateral hindpaw tests for von Frey thresholds, unweighting, warmth, and edema. One fracture cohort had no treatment, one cohort received daily i.p. injections of LY303870 $(20 \mu \mathrm{g} / \mathrm{kg})$ for 8 days prior to cast removal, and one cohort received a single intraplantar injection of LY303870 (50 $\mu \mathrm{g} / 50 \mu \mathrm{l} 0.9 \%$ saline) the day after cast removal. At one hour after intraplantar injection of LY303870 the rats were tested.

To evaluate the role SP signaling plays in post-fracture keratinocyte proliferation in the injured limb, tibial fracture rats were treated with vehicle or LY303870 (20 mg/kg i.p.) daily for 8 days prior to cast removal. All rats were injected with $\mathrm{BrdU}$ (50 mg/kg i.p.) daily for 8 days prior to cast removal. After cast removal the hindpaw skin was harvested bilaterally for coimmunostaining with anti-BrdU (DNA synthesis marker) and anti-keratin (keratinocyte marker) antibodies. Confocal microscopy was used to measure the number of BrdU-positive cells in the epidermis $(n=9$ rats for the control, ipsilateral fracture (FX-IPSI), and contralateral fracture (FX-CONTRA) cohorts, and $n=4$ for the LY303870 treatment group), and to measure epidermal thickness ( $\mathrm{n}=7$ per cohort).

To test the hypothesis that SP signaling mediates fracture-induced inflammatory mediator expression in the hindpaw skin, three cohorts of rats were evaluated; controls, vehicle-treated fractured rats, and LY303870treated fractured rats $(\mathrm{n}=13$ to 16 per cohort). LY303870 (20 mg/kg) was given by i.p. injection daily for 8 days prior to cast removal. After the casts were removed at 4 weeks post-fracture the animals were euthanized and the hindpaw skin collected for TNF- $\alpha$, IL-1 $\beta$, IL-6, and NGF protein level determination by EIA. The bilateral femurs were collected for ex vivo $\mu \mathrm{CT}$ of the proximal metaphyseal trabecular and the midfemoral cortical bone to test the hypothesis that facilitatedSP signaling contributes to periarticular bone loss after fracture.

\section{Statistical analysis}

Statistical analysis was accomplished using a two-way analysis of variance (ANOVA) followed by Bonferroni post hoc tests for the time course of the SP injection at various concentrations. One-way ANOVA was employed followed by Neuman-Keuls multiple comparison test to compare among the control, fractured and LY303870treated fractured rats. All data are presented as the mean \pm standard error (SE) of the mean, and differences are considered significant at a $P$-value less than 0.05 (Prism 5, GraphPad Software, San Diego, CA, USA). 

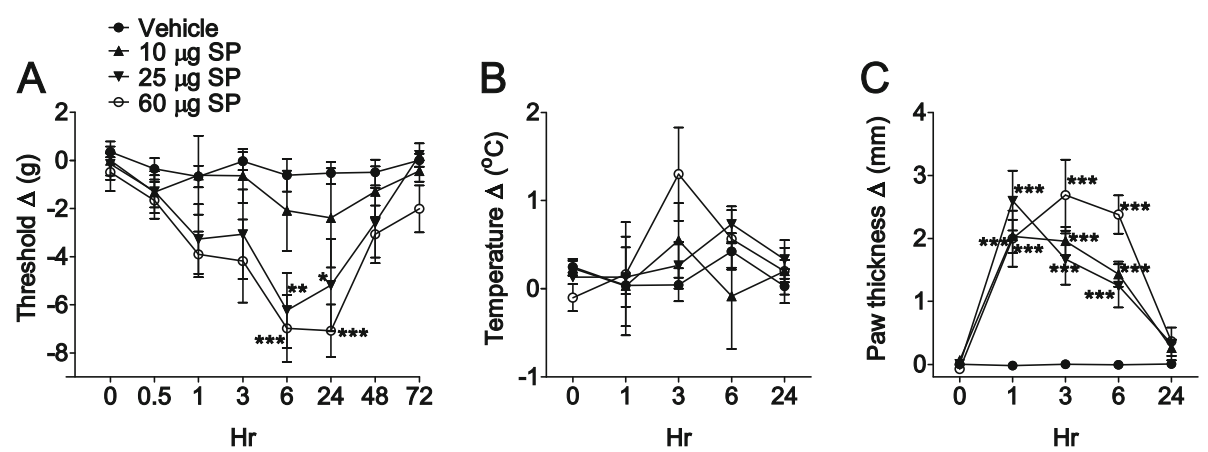

Figure 1 Intraplantar injection of 10, 25, or $60 \mu \mathrm{g}$ of substance $\mathrm{P}(\mathrm{SP})$ into the hindpaw of a normal rat dose-dependently induced mechanical allodynia to von Frey testing. (A) Allodynia developed slowly, peaking at $6 \mathrm{~h}$ post-injection, and gradually resolving over $48 \mathrm{~h}$. (B) There were no changes in hindpaw temperature after injecting any dose of SP. (C) Even the lowest dose of SP (10 $\mu \mathrm{g})$ evoked hindpaw edema within 5 minutes, peaking at $1 \mathrm{~h}$, and then gradually resolving over $24 \mathrm{~h}$. Measurements for (A), (B), and (C) represent the difference between the injected side and the contralateral paw; thus, a positive value represents an increase in temperature or paw thickness on the injected side, and a negative value represents a decrease in mechanical nociceptive thresholds on the injected side. Data were analyzed to compare SP injection vs. vehicle injection cohorts at various time points by two-way analysis of variance (ANOVA) followed by Bonferroni post hoc test. ${ }^{*} P<0.05$, ${ }^{*} P<0.01$ and ${ }^{* *} P<0.001, S P$ - vs. vehicle-injected rats at indicated time points ( $n=6$ for each injection group). (B) There was no significant difference in hindpaw temperature between SP-injected and vehicle-injected rats at any time point. (C) Injection of SP at all concentrations (10, 25, and $60 \mu \mathrm{g}$ ) significantly evoked edema at all three time points of $1 \mathrm{~h}, 3 \mathrm{~h}$ and $6 \mathrm{~h}$ (*** $<0.001 \mathrm{SP}$ - vs. vehicle-injected cohorts).

Hindpaw temperature, thickness, and mechanical nociceptive thresholds data were analyzed as the difference between the treatment side and the contralateral untreated side. Right hindpaw weight bearing data were analyzed as a ratio between the right hindpaw weight and the sum of the right $(\mathrm{R})$ and left $(\mathrm{L})$ hindpaws values $((2 \mathrm{R} /(\mathrm{R}+\mathrm{L})) \times 100 \%)$.

\section{Results}

Time course and dosage for SP-induced allodynia, warmth, and edema in the hindpaw

To determine the time course of SP-induced pain behavior and signs of inflammation, normal rats received an intraplantar SP $(0,10,25$, and $60 \mu \mathrm{g})$ injection, and then hindpaw von Frey thresholds, temperature, and thickness were determined at $0,0.2,1,3,6,24$, and $48 \mathrm{~h}$ post-injection (Figure 1). Higher doses of SP (25 and $60 \mu \mathrm{g}$ ) caused von Frey allodynia that developed slowly, peaking at $6 \mathrm{~h}$ and resolving by $48 \mathrm{~h}$. SP injection had no effect on hindpaw temperature, but did induce a rapid onset of edema at all doses tested $(10,25$ and $60 \mu \mathrm{g}$ ), that peaked at $1 \mathrm{~h}$ or $3 \mathrm{~h}$ and resolved by $24 \mathrm{~h}$. The discrepant time courses and doses required to induce allodynia and edema suggest that different mechanisms mediate these peripheral effects of SP.

Time course for SP-induced TNF- $\alpha$, IL-1 $\beta$, and IL- 6 , and NGF expression in hindpaw skin keratinocytes

To further elucidate the mechanisms responsible for SPinduced pain behavior, TNF- $\alpha$, IL-1 $\beta$, IL- 6 , and NGF protein levels in hindpaw skin were determined by EIA at various time points after SP $(25 \mu \mathrm{g})$ intraplantar injection (Figure 2). TNF- $\alpha$ expression was upregulated at $1 \mathrm{~h}$
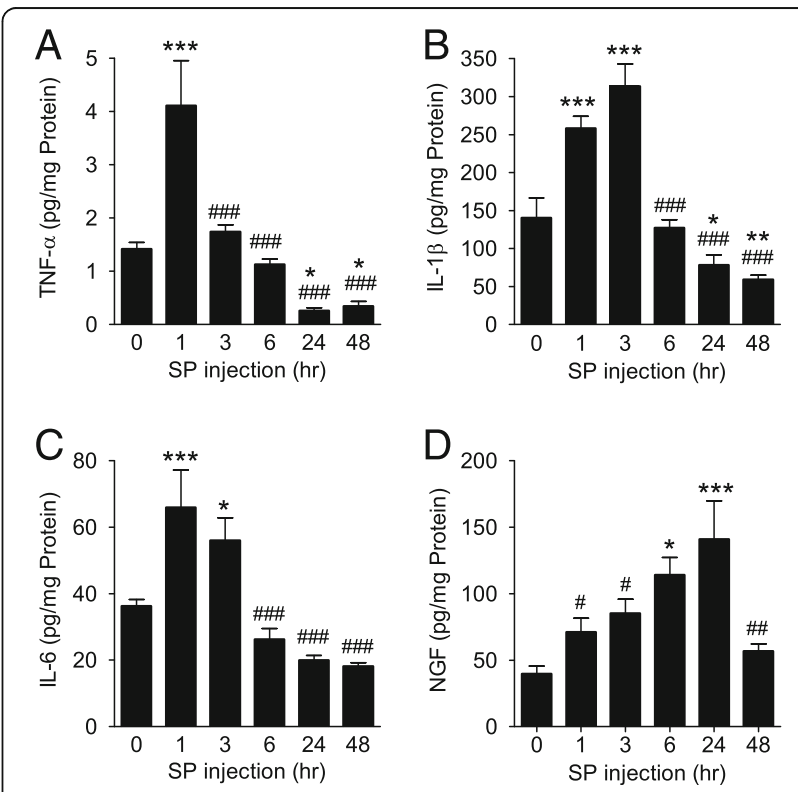

Figure 2 Cytokine TNF- $\alpha$ (A), IL-1 $\beta$ (B), IL-6 (C) and nerve growth factor (NGF) (D) production in hindpaw skin was measured by EIA assay at various time points after intraplantar injection of $\mathbf{2 5} \boldsymbol{\mu g}$ of substance P (SP). Assays were performed at $0,1,3,6,24$, and 48 h. SP injection induced a significant increase in all inflammatory mediators compared to baseline levels. TNF-a (A) was elevated at just $1 \mathrm{~h}$ after injection (compared to controls), IL-1 $\beta$ (B) and IL-6 (C) cytokine levels were elevated at $1 \mathrm{~h}$ and $3 \mathrm{~h}$ post-injection, respectively, and NGF (D) levels gradually increased over $24 \mathrm{~h}$ post-injection, dropping to baseline at $48 \mathrm{~h}$. Data are expressed as mean values (pg/mg protein) \pm standard error (SE) ( $n=8$ per cohort) and analyzed using one-way analysis of variance (ANOVA) followed by Neuman-Keuls multiple comparison test to compare different time points. ${ }^{*} P<0.05$, ${ }^{*} P<0.01$ and ${ }^{* *} P<0.001$ vs. baseline at 0 h. $\# P<0.05$, \#\# $<0.01$ and \#\#\#P<0.001 vs. peak values. 

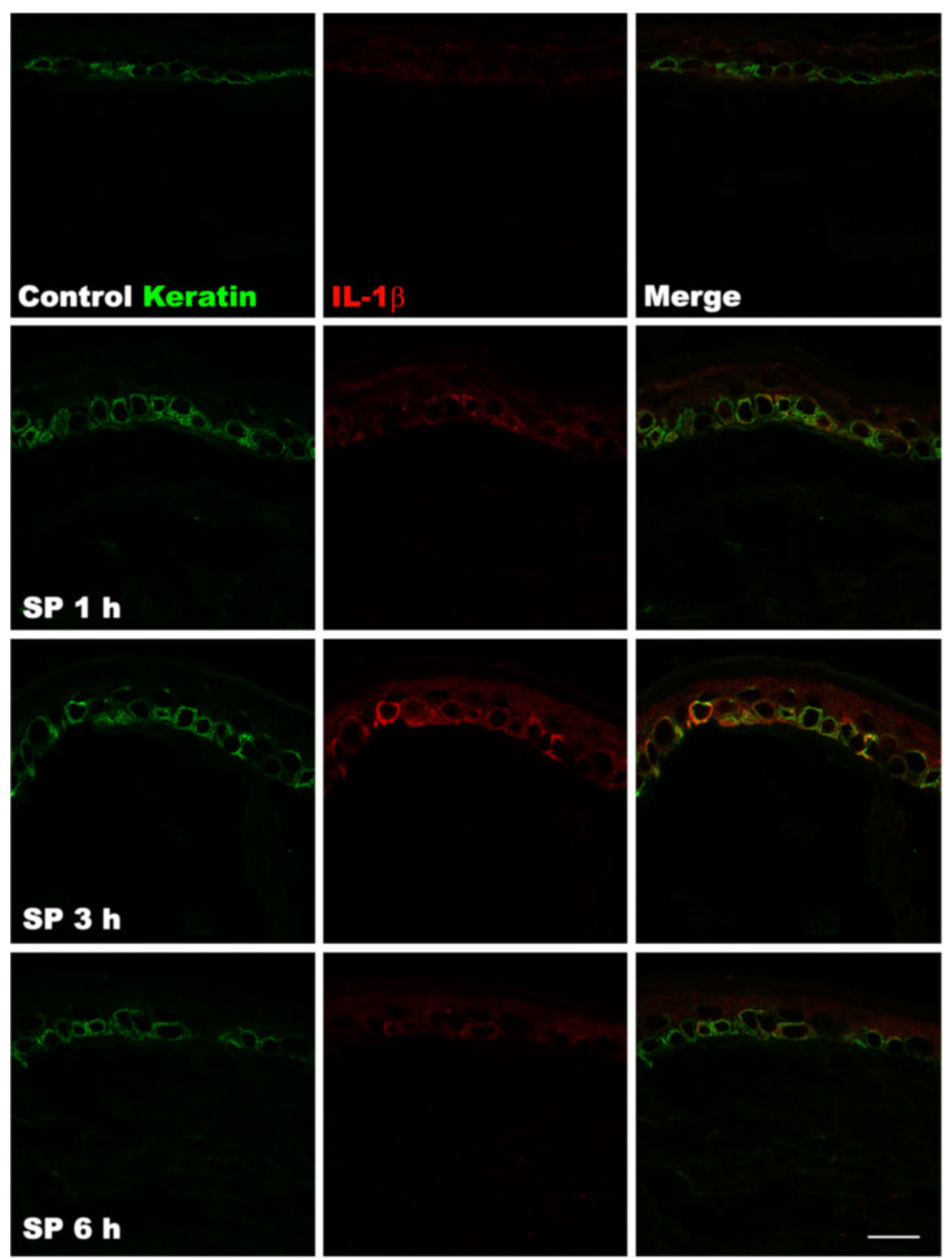

Figure 3 Immunofluorescence confocal microscopy for keratin protein and IL-1 $\beta$ in the hindpaw skin after intraplantar injection of substance $\mathbf{P}$ (SP). Kertain protein (a keratinocyte marker) (green), and IL-1 $\beta$ (red) are shown in control rats (top row of panels), and at $1 \mathrm{~h}$ (second row), $3 \mathrm{~h}$ (third row), and $6 \mathrm{~h}$ (fourth row) after intraplantar injection of $25 \mu \mathrm{g}$ SP. Increased IL-1 $\beta$ staining was observed in keratinocytes at $1 \mathrm{~h}$ and $3 \mathrm{~h}$ after SP injection, resolving by $6 \mathrm{~h}$, which corresponds to the time course observed using ElA assays in hindpaw skin homogenates (Figure 2). Scale bar $=20 \mu \mathrm{m}$.

post-injection, IL- 6 and IL- $1 \beta$ levels were increased at $1 \mathrm{~h}$ and $3 \mathrm{~h}$ post-injection, respectively, and NGF expression gradually increased from $1 \mathrm{~h}$ to $24 \mathrm{~h}$ post-injection, resolving by $48 \mathrm{~h}$. Interestingly, the time course of postinjection NGF upregulation most closely paralleled the time course observed for SP-induced allodynia. When the hindpaw skin was harvested at various time points after SP $(25 \mu \mathrm{g})$ injection for immunostaining with IL-1 $\beta$ antibody, increased IL-1 $\beta$ protein was observed in keratinocytes at $1 \mathrm{~h}$ and $3 \mathrm{~h}$ after SP injection, resolving by $6 \mathrm{~h}$, which corresponds to the time course observed using EIA assays on skin homogenates (Figure 3). Similarly, when hindpaw skin was immunostained for NGF, increased levels of NGF were observed in the keratinocytes at 1, 3, and $6 \mathrm{~h}$ after SP injection (Figure 4). In addition, an experiment was carried out to examine NK1 receptor expression after SP injection. Immunostaining demonstrated increased NK1 receptor protein in the 

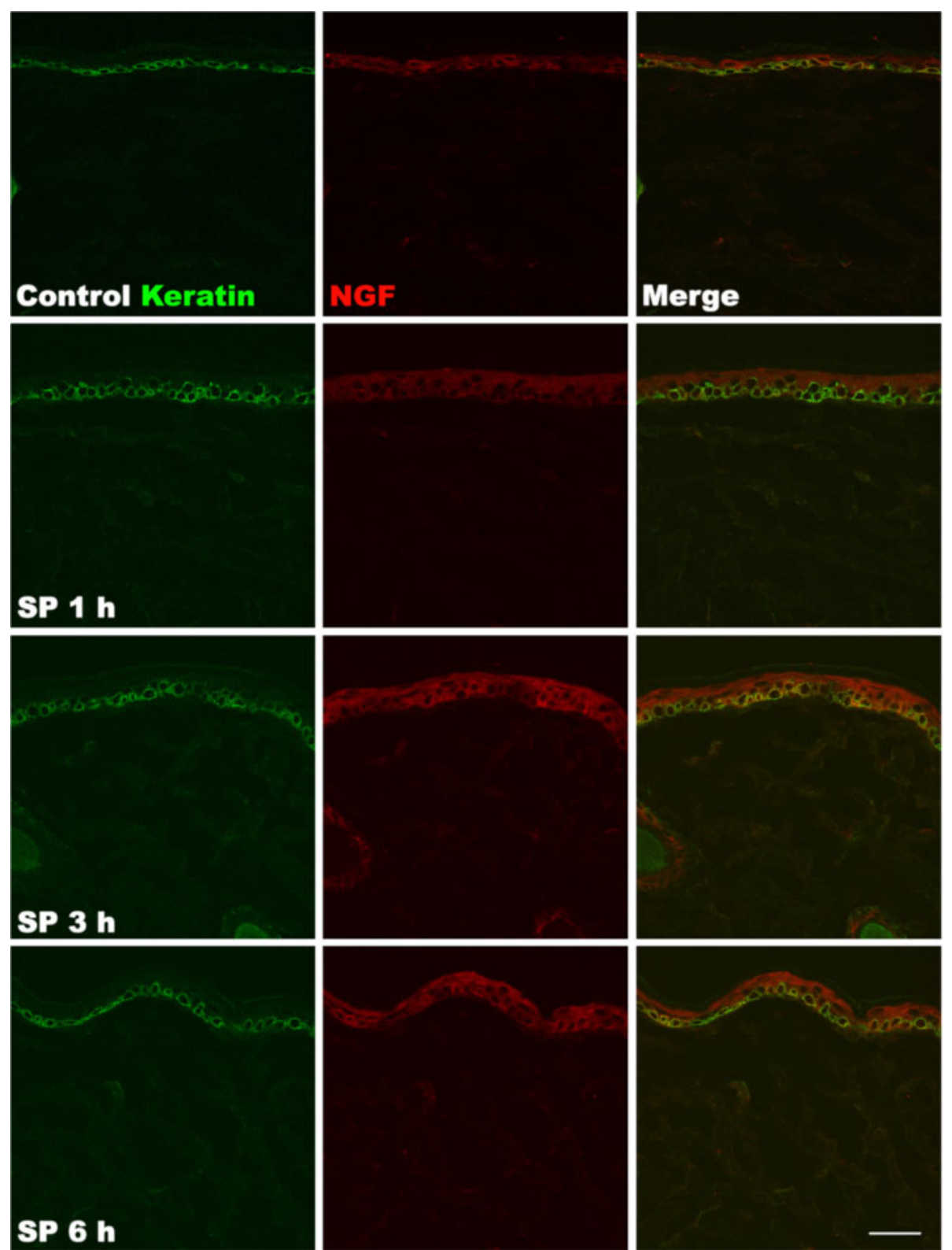

Figure 4 Co-immunostaining for keratin protein and nerve growth factor (NGF) in the hindpaw skin after intraplantar injection of substance P (SP). Keratin protein (green) and NGF (red) are shown in control rats (top row of panels), and at $1 \mathrm{~h}$ (second row), $3 \mathrm{~h}$ (third row), and $6 \mathrm{~h}$ (fourth row) after intraplantar injection of $25 \mu \mathrm{g}$ SP. Increased NGF staining was observed in keratinocytes at 1, 3 and $6 \mathrm{~h}$ after SP injection, corresponding to the prolonged allodynia observed after SP injection (Figure 1). Scale bar $=40 \mu \mathrm{m}$.

keratinocytes at $1 \mathrm{~h}$ and $3 \mathrm{~h}$ after SP injection, resolving by $6 \mathrm{~h}$ (Figure 5).

\section{Effects of anti-NGF antibody on SP-evoked nociceptive} and vascular abnormalities

The effects of anti-NGF treatment on SP-evoked hindpaw mechanical sensitivity, warmth, and edema were monitored for 72 h. Figure 6 illustrates that von Frey nociceptive thresholds in the right hindpaw were reduced after SP $(25 \mu \mathrm{g})$ intraplantar injection but anti-
NGF antibody treatment (muMab 911, $10 \mathrm{mg} / \mathrm{kg}$ i.p., given 3 days prior to testing) completely blocked the development of this mechanical allodynia. Anti-NGF antibody had no effect on hindpaw temperature or on SP-evoked hindpaw edema.

\section{Effects of systemic or localized LY303870 treatment on} fracture-induced nociceptive and vascular abnormalities These experiments tested the hypothesis that SP signaling in the hindpaw skin is responsible for fracture-induced 

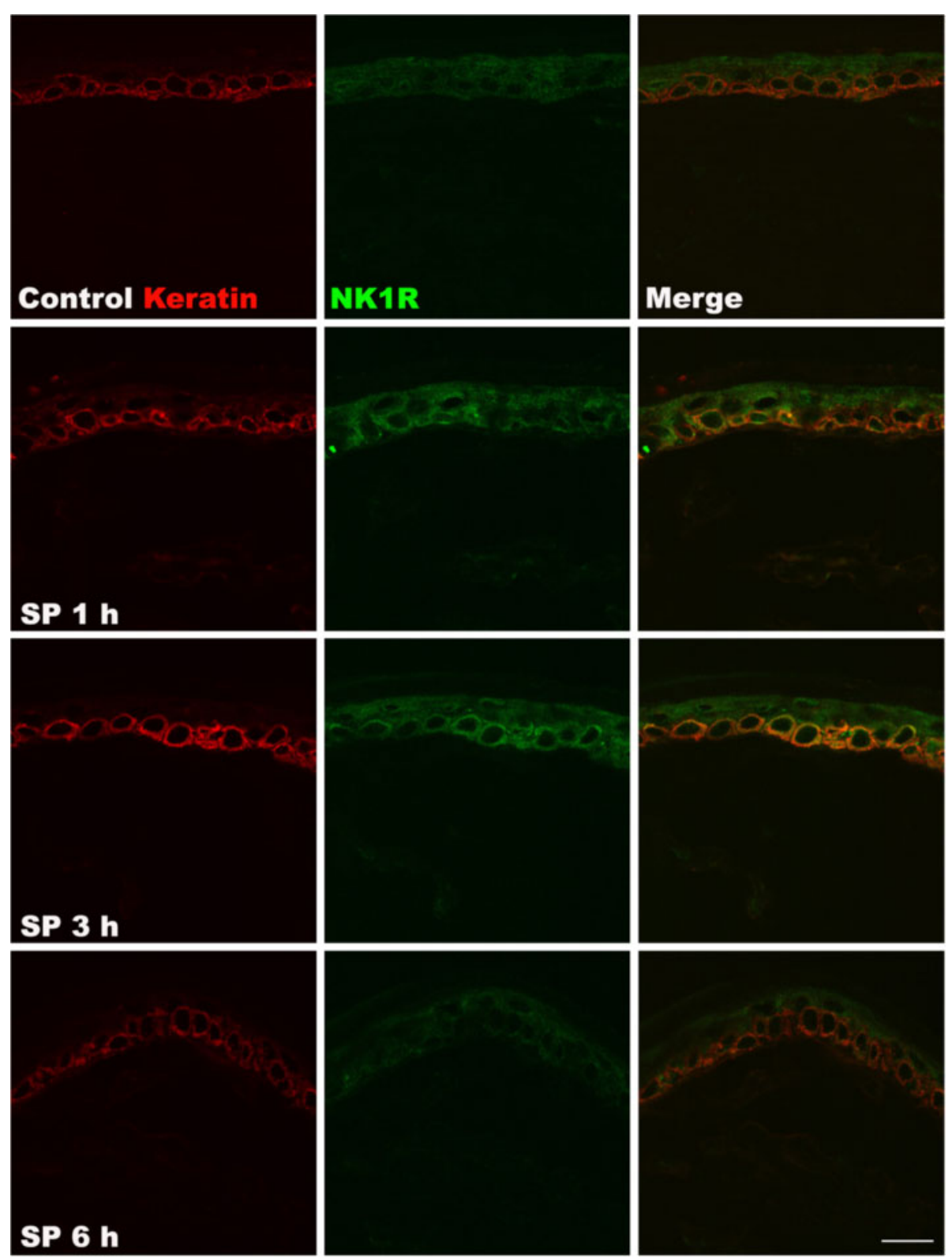

Figure 5 Labeling for keratin protein and the NK1 receptor (NK1R) in the hindpaw skin after intraplantar injection of substance P (SP). Keratin protein (red) and NK1R (green) are shown in control rats (top row of panels), and at $1 \mathrm{~h}$ (second row), $3 \mathrm{~h}$ (third row), and $6 \mathrm{~h}$ (fourth row) after intraplantar injection of $25 \mu \mathrm{g} \mathrm{SP}$. Increased NK1R staining was observed in keratinocytes at $1 \mathrm{~h}$ and $3 \mathrm{~h}$ after SP injection, resolving by $6 \mathrm{~h}$ post-injection. These results suggest that facilitated SP signaling is not responsible for the prolonged hyperalgesia observed after SP injection (Figure 1). Scale bar $=20 \mu \mathrm{m}$.

nociceptive and vascular changes. Rats underwent tibial fracture and cast immobilization for 4 weeks, then the cast was removed and on the following day the rats were tested for hindpaw allodynia, unweighting, warmth and edema. Fracture reduced von Frey nociceptive thresholds in the fractured hindpaw from 0.88 to $-8.97 \mathrm{~g}$ (Figure 7). Untreated fracture rats unweighted the ipsilateral hindpaw by $43 \%$. Fracture also increased hindpaw skin temperature by $5.2^{\circ} \mathrm{C}$ and thickness by $1.7 \mathrm{~mm}$. When the NK1 receptor antagonist LY303870 (20 $\mathrm{mg} / \mathrm{kg} /$ day $)$ was injected i.p. for 8 consecutive days prior to cast removal there was a reduction in hindpaw allodynia, unweighting, warmth, and edema by $83,80,64$, and $67 \%$, respectively. Similarly, a single intraplantar injection of LY303870 $(50 \mu \mathrm{g} / 50 \mu \mathrm{l}$ saline) into the hindpaw skin of the fractured limb $1 \mathrm{~h}$ prior to behavioral testing also reduced hindpaw allodynia and unweighting, but had no effect on temperature or edema. These results suggest that 

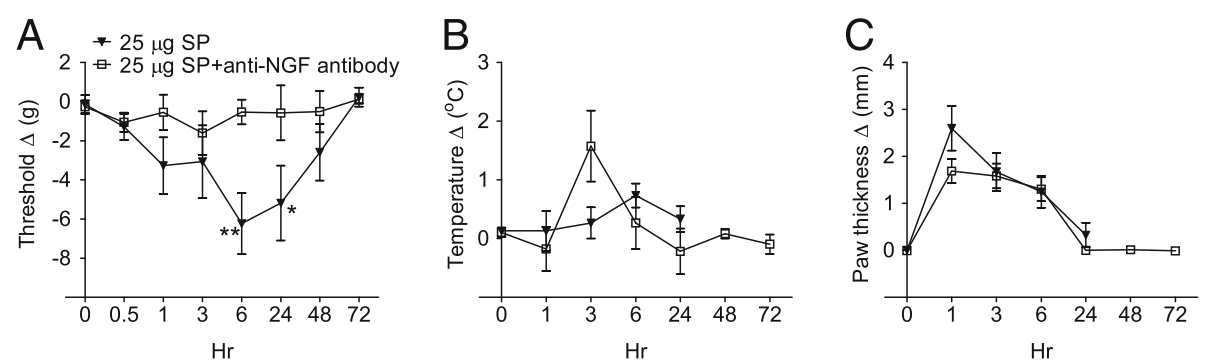

Figure 6 This experiment tested the hypothesis that the delayed onset, long lasting allodynia evoked by intraplantar injection of substance $\mathbf{P}$ (SP) was mediated by increased nerve growth factor (NGF) expression in skin keratinocytes. Rats ( $\mathrm{n}=8$ per cohort) were treated with either anti-NGF antibody (10 mg/kg i.p. muMab 911) or vehicle, 3 days prior to undergoing intraplantar SP (25 $\mu$ g) injection. (A) SP injection induced a slowly developing von Frey allodynia that peaked at $6 \mathrm{~h}$ post-injection, but SP-induced allodynia was blocked by pretreatment with anti-NGF. (B) There were no changes in hindpaw temperature after injecting SP. (C) Anti-NGF pretreatment had no effect on SP-evoked hindpaw edema. Measurements for $(\mathbf{A}),(\mathbf{B})$, and $(\mathbf{C})$ represent the difference between the injected side and the contralateral paw, thus a positive value represents an increase in temperature or paw thickness on the injected side; a negative value represents a decrease in mechanical nociceptive thresholds on the injected side. Behavioral data after SP injection were analyzed by two-way analysis of variance (ANOVA) followed by Bonferroni post hoc test to compare differences between rats pretreated with and without anti-NGF antibody at indicated time points. ${ }^{*} P<0.05$ and ${ }^{*} P<0.01$ vehicle vs. anti-NGF antibody pretreatments.

SP signaling in the hindpaw skin contributes to the maintenance of pain behavior in the injured limb at 4 weeks post-fracture. We suspect that the discrepancy between the effects of systemic and intraplantar LY303870 in reversing post-fracture hindpaw warmth and edema reflect the brief duration of the intraplantar LY303870 injection effect. The very low dose $(50 \mu \mathrm{g}$, or approximately $0.1 \mathrm{mg} / \mathrm{kg}$ ) of LY303870 used in the intraplantar injection experiment had no behavioral effects when given systemically, and the analgesic effects observed after intraplantar LY303870 injection resolved by $2 \mathrm{~h}$ post-injection (data not shown), suggesting that the drug had dispersed systemically within $2 \mathrm{~h}$ post-injection and was no longer reaching effective concentrations in the hindpaw skin.

\section{Effects of LY303870 on fracture-induced hindpaw keratinocyte proliferation and epidermal hyperplasia} We previously observed that distal tibial fracture led to chronic keratinocyte proliferation and epidermal hyperplasia in the hindpaw skin [8] and we hypothesized that SPsignaling was responsible for fracture-induced hindpaw keratinocyte proliferation. To test this hypothesis, BrdU
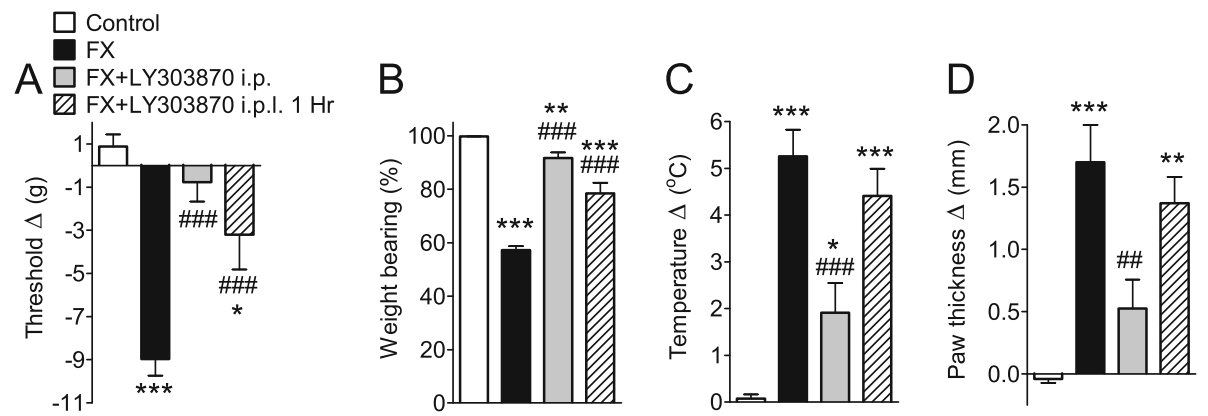

Figure 7 Three cohorts of rats underwent right distal tibial fracture and hindlimb cast immobilization for four weeks. After baseline testing, rats were divided into 4 groups. One fracture ( $F X)$ group had no other treatment ( $F X, n=16)$, another fracture group underwent daily intraperitoneal (i.p.) injections with the NK1 receptor antagonist LY303870 (20 mg/kg i.p., FX + LY303870 i.p., $n=15)$ over an 8-day interval prior to cast removal, and another fracture group underwent a single intraplantar (i.p.l) injection of LY303870 (50 $\mu \mathrm{g})$ on the day after cast removal and $1 \mathrm{~h}$ prior to testing ( $\mathrm{FX}+\mathrm{LY} 303870$ i.p.l. $1 \mathrm{~h}, \mathrm{n}=8$ ). At four weeks post-fracture the 8 days of systemic LY303870 treatment reduced hindpaw mechanical allodynia (A), unweighting (B), warmth (C) and edema (D) that developed after fracture. In addition, all four tests were carried out $1 \mathrm{~h}$ after the intraplantar injection of LY303870. A single intraplantar injection of LY303870 also reduced allodynia and unweighting, but had no effect on warmth or edema. Measurements for $(\mathbf{A}),(\mathbf{C})$, and (D) represent the difference between the fracture side and the contralateral paw, thus a positive value represents an increase in temperature or thickness on the fracture side; a negative value represents a decrease in mechanical nociceptive thresholds on the affected side. Measurements for (B) represent weight-bearing on the fracture hindlimb as a ratio to $50 \%$ of bilateral hindlimb loading, thus a percentage lower than 100\% represents hindpaw unweighting. Data were analyzed using one-way analysis of variance (ANOVA) followed by Neuman-Keuls multiple comparison test. ${ }^{*} P<0.05,{ }^{* *} P<0.01,{ }^{* * *} P<0.001$ fracture vs. control $(n=13)$ values, and ${ }^{\# \#} P<0.01$

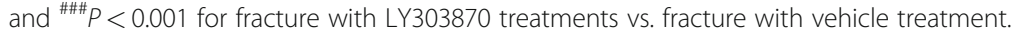



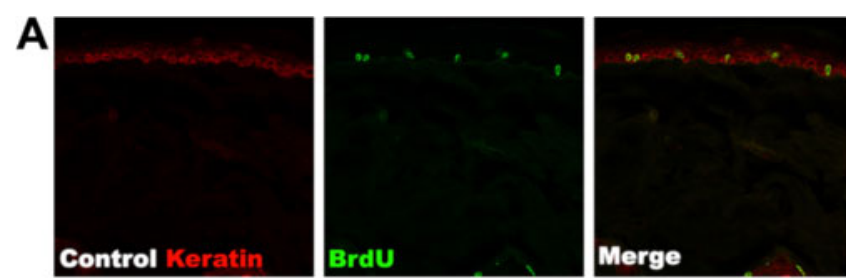

B
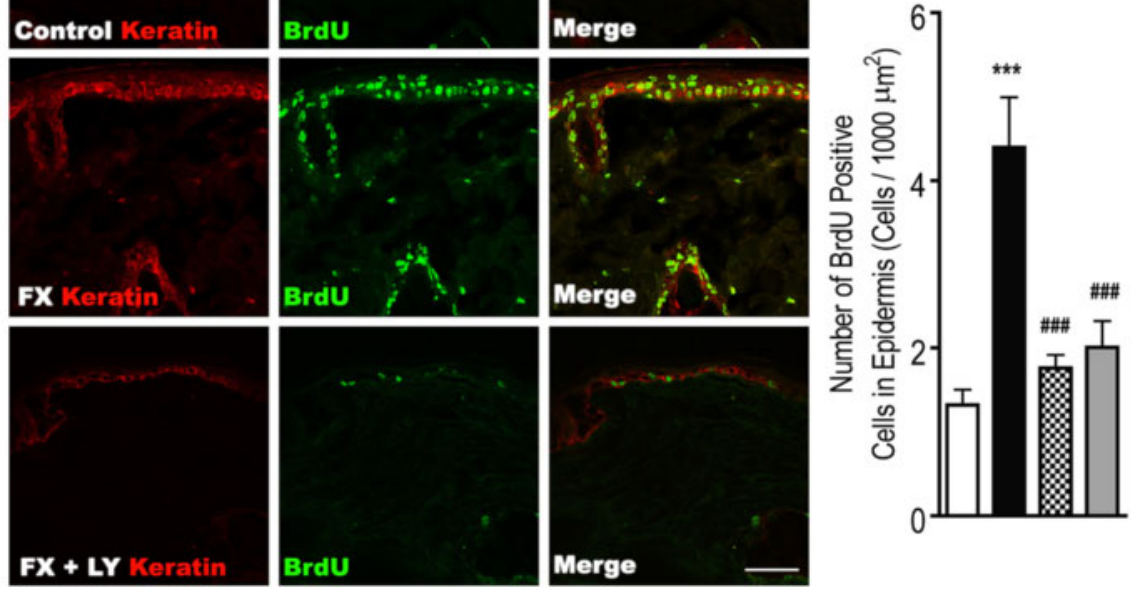

Figure 8 Co-immunostaining for keratin and bromo-2-deoxyuridine (BrdU) in the hindpaw skin four weeks post-fracture. (A) Top panels are images from a normal control rat, middle panels are from a fracture rat, and lower panels are from a fracture rat treated with an NK1 receptor antagonist (LY303870 20 mg/kg, i.p. daily for 8 days), showing keratin staining (red) and BrdU (a marker of DNA synthesis) staining (green).

Fracture increased BrdU staining in keratinocytes, indicating increased cellular proliferation, and LY303870 treatment prevented this increase. Scale bar $=50 \mu \mathrm{m}$. (B) There was a 3.3 fold increase in BrdU-positive cell numbers at 4 weeks post-fracture in the ipsilateral fracture paw (FX-IPSI), but not in the contralateral paw (FX-CONTRA), and this increase was blocked in fractured rats treated with LY303870 (FX + LY303870). Data were analyzed using one-way analysis of variance (ANOVA) followed by Neuman-Keuls multiple comparison test. ${ }^{* * *} P<0.001$ for FX-IPSI ( $n=9$ ) vs. control $(n=9)$, and ${ }^{\# \# \#} P<0.001$ for FX + LY303870 $(n=4)$ and FX-CONTRA $(n=9)$ vs. FX-IPSI cohorts.

was used to label DNA synthesis in proliferating keratinocytes. Figure 8 shows representative confocal images of BrdU (green) and keratin (a keratinocyte marker, red) in hindpaw skin sections from control rats, from the ipsilateral hindpaw of 4-week post-fracture rats, and from the ipsilateral hindpaw of 4 week post-fracture rats treated with LY303870 (20 mg/kg/day for 8 days just prior to cast removal). Only a few BrdU-positive cells were detected in control skin (Figure 8A, upper row of panels), but skin sections from fracture rats demonstrated a large number of BrdU-positive cells in the epidermis co-labeled for keratin, including the basal layer where new keratinocytes are generated (Figure $8 \mathrm{~A}$, middle row of panels). Interestingly, LY303870 treatment blocked the fracture-induced increase in BrdU-positive cell numbers in the epidermis (Figure 8A, bottom row of panels). Quantitation of the BrdU-positive cells in hindpaw skin revealed a 2.3 fold increase in BrdU-positive cells in the fractured limb (FXIPSI) compared to the control (Figure 8B). No increase in BrdU-positive cells was observed in the hindpaw contralateral to the fractured limb (FX-CONTRA). Furthermore, LY303870 treatment reversed the fracture-evoked increase of BrdU-positive cell number in the epidermis (Figure 8B).

To evaluate epidermal thickening after fracture, hindpaw skin sections were stained for keratin (green) (Figure 9).
Consistent with the BrdU results, we observed that fracture increased epidermal thickness and that the treatment with LY303870 for 8 days prior to cast removal blocked epidermal thickening. These results support the hypothesis that SP signaling is responsible for fractureinduced keratinocyte proliferation and epidermal hyperplasia in the hindpaw skin.

Effects of LY303870 on fracture-induced TNF- $\alpha$, IL-1 $\beta$, IL-6, and NGF expression in hindpaw skin

To elucidate the involvement of SP signaling in fractureinduced upregulation of TNF- $\alpha$, IL- $1 \beta$, IL- 6 , and NGF, fractured rats were injected with LY303870 $(20 \mathrm{mg} / \mathrm{kg} /$ day, i.p.) or vehicle for 8 consecutive days prior to behavioral testing and skin harvesting at 4 weeks post-fracture. Cytokines and NGF were determined by EIA of hindpaw skin homogenates. Figure 10 illustrates that TNF- $\alpha$, IL- $1 \beta$, IL-6 and NGF protein levels in the hindpaw skin were increased by $1593,176,33.9$, and $495 \%$, respectively, at 4 weeks after tibial fracture. LY303870 treatment reversed the fracture-induced upregulation of these proinflammatory cytokines and NGF, by $69.9,105.9,171.6$, and $91.5 \%$, respectively, indicating that SP signaling plays a critical role in post-fracture inflammatory mediator expression. 


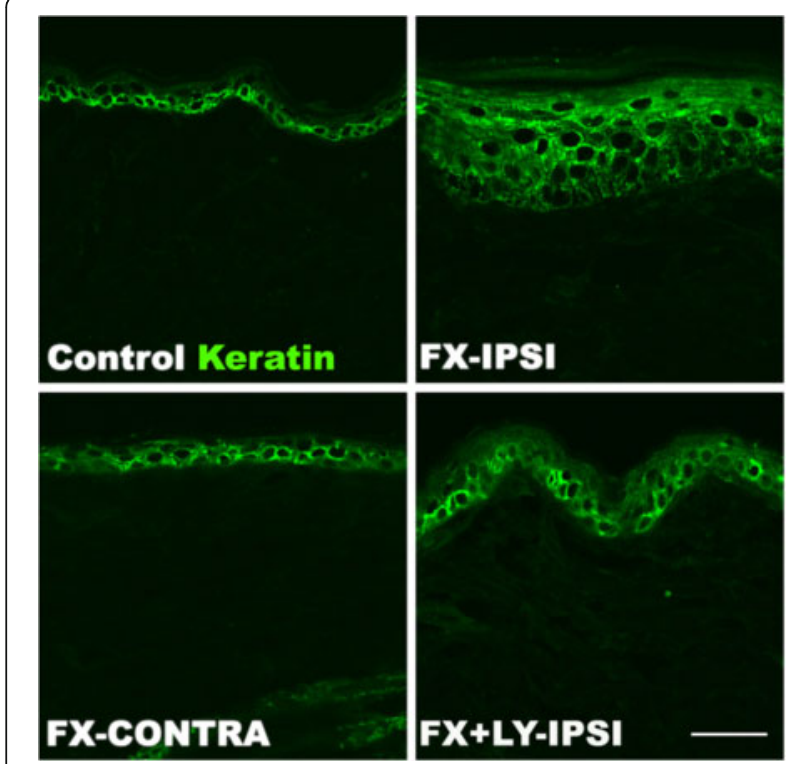

Figure 9 Immunostaining for keratin in the hindpaw skin four weeks post-fracture. Panels exhibit confocal images from the hindpaw skin of a normal control rat, the ipsilateral hindpaw skin of a fracture rat (FX-IPSI), the contralateral hindpaw skin of a fracture rat (FX-CONTRA), and the ipsilateral hindpaw skin of a fracture rat treated with an NK1 receptor antagonist (LY303870 20 mg/kg, i.p. daily for 8 days, FX + LY-IPSI), showing staining for keratin (green). Scale bar $=25 \mu \mathrm{m}$. There was an increase in epidermal thickness, indicating increased keratinocyte proliferation, at 4 weeks postfracture in the fracture paw (FX-IPSI), but not in the contralateral paw (FX-CONTRA), and this increase was blocked in fractured rats treated with LY303870 (FX+ LY-IPSI).

\section{Effects of LY303870 on fracture-induced bone loss}

At 4 weeks post-fracture there was significant reduction in trabecular \% $\mathrm{BV} / \mathrm{TV}$ in the distal femur ipsilateral, but not contralateral to the tibial fracture $(n=10$ per cohort) (Table 1). Distal femoral TbTh and ConnD were also reduced after fracture. No changes were observed in
$\%$ BAr/TtAr after fracture. Treatment with the NK1 receptor antagonist LY303870 (20 mg/kg/day i.p. for 8 days just prior to cast removal) had no effect on bone loss in the distal femur, suggesting that SP signaling through the NK1 receptor does not contribute to the periarticular trabecular bone loss observed after tibial fracture.

\section{Discussion}

Substantial evidence exists to suggest that neuropeptide mediated mechanisms support pain and edema in CRPS. Using a rat model involving tibial fracture and cast immobilization that faithfully reproduces many of the features of CRPS type I in humans, we previously showed that SP signaling through the NK1 receptor was required for the full manifestation of the syndrome [2]. Similar findings were reported using a sciatic section model of CRPS type II, a condition defined as involving frank damage to a peripheral nerve [27]. Unknown, however, is the mechanism through which SP acts to cause the CRPSrelated changes. Additional data suggest that cytokines such as TNF- $\alpha$, IL-1 $\beta$, and IL- 6 , as well as the neurotrophin NGF, might contribute to pain and vascular changes in CRPS $[4,5,7,8]$. Therefore, we set out to determine if SP-supported production of any of these mediators contributes to the CRPS phenotype in the rat fracture/cast model. We found that 1) the time course of NGF production after intradermal CRPS injection most closely matched the time course of SP-mediated nociceptive sensitization; 2) SP-stimulated NGF production was localized to the epidermal keratinocytes; 3 ) anti-NGF could completely block the nociceptive changes but not the vascular effects of SP; 4) the blockade of SP signaling using the NK1 receptor antagonist LY303870 effectively reduced nociceptive and vascular manifestations of CRPS in the fracture/cast model, but not bone-related changes; 5 ) the keratinocyte proliferation characteristic of CRPS in the rat model was dependent on SP signaling, and 6) LY303870 blocked the
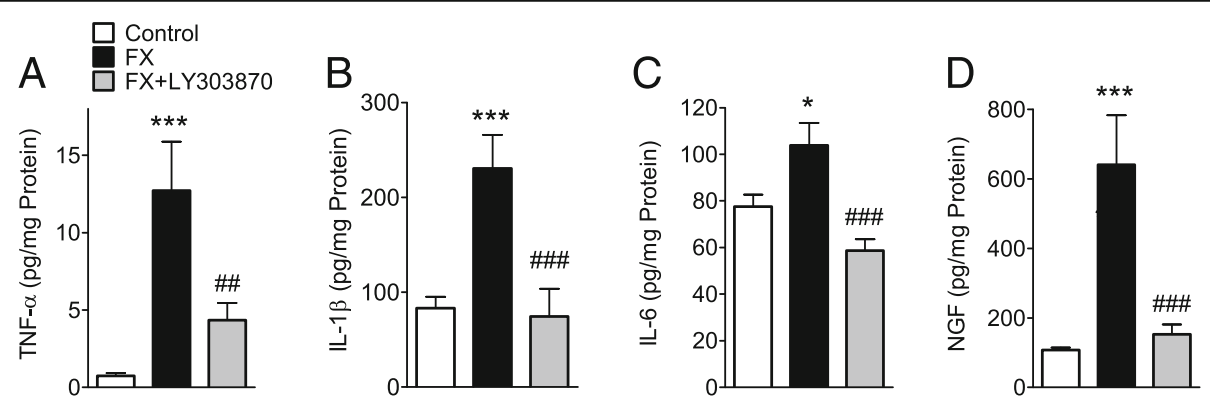

Figure 10 Cytokine TNF- $\alpha$ (A), IL-1 $\beta$ (B), IL-6 (C) and nerve growth factor (NGF) (D) levels in hindpaw skin were measured by EIA assay at four weeks post-fracture. Rats were treated with vehicle $(F X, n=16)$ or the NK1 receptor antagonist LY303870 (20 mg/kg i.p. daily for 8 days just prior to cast removal, $F X+L Y 303870, n=15)$. Fracture induced an increase in all inflammatory mediators compared to controls and this was blocked in the LY303870-treated fractured rats. Data are expressed as mean values (pg/mg protein) \pm standard error (SE). Data were analyzed using one-way analysis of variance (ANOVA) followed by Neuman-Keuls multiple comparison test. ${ }^{*} P<0.05$ and ${ }^{* * *} P<0.001$ vs. untreated controls $(\mathrm{n}=13),{ }^{\# \#} P<0.01$ and ${ }^{\# \# \#} P<0.001$ for $\mathrm{FX}+\mathrm{LY} 303870$ vs. fracture. 
production of NGF as well as several cytokines in the skin of the fracture/cast rats. Together these results indicate that while SP has many effects related to the manifestations of CRPS, it is the stimulation of NGF production that seems to be most closely related to supporting nociceptive sensitization.

Neuropeptides, most notably SP, have been implicated in the pathophysiology of CRPS in both humans and, correspondingly, in animal models. Analysis of venous blood showed elevation of SP in CRPS patients [29]. When SP was administered to CRPS skin through microdialysis fibers, enhanced levels of protein extravasation were seen relative to the responses in unaffected individuals [11]. Furthermore, electrical stimulation of the limbs of patients with CRPS leads to greater neuropeptide-dependent protein extravasation than in control individuals [9]. It is notable that the use of angiotensin converting enzyme inhibitors leads to an apparent increased risk for the development of CRPS [30]. These agents slow the breakdown of SP.

Previously reported animal studies support these observations. For example, animals deficient in the endogenous SP-metabolizing enzyme, neutral endopeptidase (NEP), develop greater nociceptive and limb neurogenic changes after chronic constriction injury (CCI) [31]. As mentioned above, previous experiments from our own laboratory demonstrated that NK1 antagonism inhibited nociceptive sensitization in models of both CRPS I and II $[2,27]$. It may also be relevant that SP-deficient mice have less robust allodynia and cytokine generation in skin after hindpaw incision [32], and that NK1 receptor antagonists have been demonstrated to be effective analgesics for post-operative pain in a clinical trial [33] (though not in trials involving other types of pain). While no clinical trial data are currently available examining NK1 receptor antagonist efficacy in CRPS, future trials might have their greatest opportunity for success in patients with acute or warm-phase CRPS syndrome where neurogenic inflammation is most prominent. This is the time period most similar to the rodent model used in these studies.

Our studies went beyond the simple description of NK1 control of specific cytokines and NGF in paw skin after SP administration and in the fracture model of CRPS. We attempted to determine which of the several mediators was most closely linked to SP's pro-nociceptive effects. Based on the time course of production and the time course for nociceptive sensitization, NGF appeared to be the most plausible candidate. In fact, anti-NGF was able to block the pro-nociceptive effects of SP, but not the vascular effects, which follow a distinctly shorter time course. Earlier studies demonstrated that the same antiNGF reagent blocked nociceptive sensitization but not the production of other inflammatory mediators in the fracture model [5]. The NK1 receptor antagonist also blocked NGF production in the fracture model. Furthermore, the current study demonstrated that epidermal keratinocytes are the cellular source for cutaneous NGF after SP injection. Both rodents and humans express NK1 receptors on keratinocytes [14,34]. It seems reasonable to hypothesize that NGF formed in the epidermis stimulates TrkA, expressing primary afferent neurons leading to nociceptive sensitization [35]. NGF receptors on vascular tissue are far less well described. Though data from human trials conducted on CRPS patients are

Table 1 Effects of fracture on trabecular and cortical bone parameters assessed by ex vivo $\mu \mathrm{CT}$

\begin{tabular}{|c|c|c|c|c|c|}
\hline & Control & $\begin{array}{l}\text { Fracture } \\
\text { ipsilateral }\end{array}$ & $\begin{array}{l}\text { Fracture + LY } \\
\text { ipsilateral }\end{array}$ & $\begin{array}{l}\text { Fracture } \\
\text { contralateral }\end{array}$ & $\begin{array}{l}\text { Fracture }+\mathrm{LY} \\
\text { contralateral }\end{array}$ \\
\hline \multicolumn{6}{|l|}{ Distal femur } \\
\hline BV/TV (\%) & $12.5 \pm 0.6$ & $6.60 \pm 1.22^{* * *}$ & $7.31 \pm 0.72^{* * *}$ & $10.63 \pm 1.27$ & $11.13 \pm 0.84^{*}$ \\
\hline $\mathrm{TbN}\left(\mathrm{mm}^{-1}\right)$ & $2.78 \pm 0.08$ & $2.38 \pm 0.17$ & $2.43 \pm 0.14$ & $2.91 \pm 0.17$ & $2.87 \pm 0.15$ \\
\hline TbTh $(\mu \mathrm{m})$ & $65.3 \pm 1.1$ & $57.6 \pm 2.2^{* * *}$ & $62.1 \pm 1.2^{* * *}$ & $63.2 \pm 2.2$ & $66.5 \pm 1.2$ \\
\hline $\operatorname{TbSp}(\mu \mathrm{m})$ & $372 \pm 11$ & $441 \pm 31$ & $428 \pm 25$ & $358 \pm 22$ & $360 \pm 18$ \\
\hline ConnD $\left(1 / \mathrm{mm}^{3}\right)$ & $40.0 \pm 2.7$ & $14.0 \pm 4.3^{* * *}$ & $14.7 \pm 2.5^{* *}$ & $29.5 \pm 5.2^{*}$ & $29.4 \pm 3.8^{*}$ \\
\hline \multicolumn{6}{|l|}{ Femur midshaft } \\
\hline $\operatorname{BAr}\left(\mathrm{mm}^{2}\right)$ & $7.36 \pm 0.13$ & $7.42 \pm 0.13$ & $7.34 \pm 0.21$ & $7.27 \pm 0.14$ & $7.34 \pm 0.20$ \\
\hline $\operatorname{TtAr}\left(\mathrm{mm}^{2}\right)$ & $13.4 \pm 0.4$ & $13.4 \pm 0.3$ & $13.1 \pm 0.3$ & $13.2 \pm 0.3$ & $13.1 \pm 0.3$ \\
\hline $\operatorname{MeAr}\left(\mathrm{mm}^{2}\right)$ & $6.11 \pm 0.29$ & $5.99 \pm 0.22$ & $5.74 \pm 0.24$ & $5.96 \pm 0.21$ & $5.72 \pm 0.23$ \\
\hline CtTh $(\mu \mathrm{m})$ & $703 \pm 6$ & $720 \pm 7$ & $723 \pm 18$ & $707 \pm 8$ & $725 \pm 20$ \\
\hline $\mathrm{BPm}(\mathrm{mm})$ & $23.9 \pm 0.5$ & $22.4 \pm 0.4^{*}$ & $21.3 \pm 0.4^{* *}$ & $22.6 \pm 0.4$ & $21.9 \pm 0.3^{* *}$ \\
\hline $\mathrm{BAr} / \mathrm{Tt} \operatorname{Ar}(\%)$ & $54.8 \pm 0.9$ & $55.4 \pm 0.7$ & $56.2 \pm 1.3$ & $55.0 \pm 0.5$ & $56.2 \pm 1.3$ \\
\hline
\end{tabular}

Statistical significance determined from one-way analysis of variance (ANOVA) followed by post hoc Newman-Keuls test. All data are expressed as means \pm standard error of the mean. ${ }^{*} P<0.05$, ${ }^{* *} P<0.01$ and ${ }^{* * *} P<0.001$ vs. controls.

BV: bone volume; TV: total volume; TbN: trabecular number; TbTh: trabecular thickness; TbSp: trabecular separation; ConnD: connectivity density; Bar: bone area: TtAr: total cross sectional area; MeAr: medullary area; CtTh: cortical thickness; BPm: bone perimeter; LY: LY303870. 
not available, anti-NGF has the ability to reduce other forms of refractory chronic pain in humans including back pain and pain due to osteoarthritis [36-39]. Our data suggest that anti-NGF might be an effective therapy for the pain, but not the vascular changes associated with CRPS.

Skin is the body's largest organ, and keratinocytes are the most common cell type in the epidermis, the skin's outermost cellular layer. Far from performing only the function of providing a barrier against external threats, skin has a number of endocrinologic and immunologic roles. Indeed the skin has various roles in supporting pain. Recent studies of gene expression and keratinocyte function suggest that functional changes in these cells support pain in several clinical pain syndromes. For example, studies of skin biopsies from patients with both post-herpetic neuralgia and CRPS I have identified alterations in several sodium ion channel types including $\mathrm{Na}(\mathrm{v})$ 1.2, 1.2, 1.5, 1.6, 1.7 and 1.8, channels normally associated with controlling the electrical excitability of nociceptive neurons [40]. While the function of those channels in keratinocytes is somewhat unclear, recent observations describe a more plausible mechanism supporting nociception involving the expression of CGRP. The skin of patients with painful neuropathies was observed to produce the $\beta$ form of CGRP aberrantly [41]. Keratinocyte release of this neuropeptide would allow it to interact with nociceptive nerve terminals in the epidermis and to act in a paracrine and autocrine fashion on other keratinocytes, providing potential mechanisms for skin to enhance nociceptive sensitivity. Likewise we have identified cytokines such as IL-1 $\beta$, IL-6, TNF- $\alpha$ as well as NGF in the keratinocytes of mice and rats after tibial fracture and immobilization [8]. Significantly, peripherally restricted biologic antagonists to these mediators are very effective in reducing the nociceptive and related changes characteristic of CRPS I in rats $[4,5,7]$. In the present set of studies we were able to refine our understanding of the neuroinflammatory link between SP and NGF production at the cellular level in a fracture model of CRPS. Not only were NK1 receptors upregulated on keratinocytes after SP injection, but NGF production was strongly enhanced as well. Finally, we observed that SP affected more than just mediator production in keratinocytes, in that cellular proliferation was stimulated as well. Trophic changes involving the skin are characteristic of many patients with CRPS. Thus keratinocytes are affected in multiple ways by the release of SP.

A range of SP effects have been observed in models of acute and chronic pain. Signaling mediated by this molecule has been studied in translational fashion in some detail. While there have been disappointments in drug development efforts where blockade of SP signaling was hoped to have immediate analgesic benefits in otherwise normal patients [42], SP is still likely to support more complex biological pathways. It has been shown to be highly active in human skin, especially in the setting of CRPS. Our results suggest that we should focus more on SP's ability to support the production of additional downstream mediators, like NGF, in indirectly supporting nociceptive sensitization. We also need to realize that changes in the skin of patients with CRPS are complex, and that there may be no single signaling pathway adequately explaining all relevant changes. Thus the principal goal to be set for future investigations in this area might be to integrate the functions of the already identified signaling molecules, systems and cascades into a coherent representation of the pathophysiology of CRPS.

\section{Abbreviations}

ANOVA: analysis of variance; BAr: cortical bone area; $\mathrm{BAr} / \mathrm{TtAr}$ : relative cortical bone area; BPm: bone perimeter; BrdU: 5-bromo-2-deoxyuridine; BV/TV: bone volume fraction; CCl: chronic constriction injury; CGRP: calcitonin

gene-related peptide; ConnD: connectivity density; CONTRA: contralateral;

CRPS: complex regional pain syndrome; CtTh: cortical thickness; Cy3: cyanine

dye 3; FITC: fluorescein isothiocyanate; FX: Fracture; IL: interleukin;

IPSI: Ipsilateral; MeAr: medullary area; NGF: nerve growth factor- $\beta$;

NK1: neurokinin-1; OD: optical density; PBS: phosphate buffered saline;

PFA: paraformaldehyde; ROI: region of interest; SP: substance P;

TbN: trabecular number; TbSp: trabecular separation; TbTh: trabecular

thickness; TNF: tumor necrosis factor; TtAr: total cross sectional area;

$\mu C T$ : micro computer tomography.

\section{Competing interests}

The authors declare that they have no competing interests.

\section{Authors' contributions}

TW performed the biochemical assays, analyzed the data, generated figures, and contributed to the writing of the manuscript. TG generated the fracture rats, performed the behavioral experiments, analyzed the data, and generated figures. WL performed the immunohistochemistry, analyzed the data, and generated figures. SH performed $\mu \mathrm{CT}$ scanning, analyzed data and generated the table. WK participated in the design, data analysis, and editing of this manuscript. DC participated in the design, data analysis, and editing of this manuscript. All the authors have read and approved the final manuscript.

\section{Author details}

${ }^{1}$ Physical Medicine and Rehabilitation Service, Veterans Affairs Palo Alto Health Care System, Palo Alto, CA94304, USA. ${ }^{2}$ Anesthesiology Service, Veterans Affairs Palo Alto Health Care System, 3801 Miranda Avenue (112-A), Palo Alto, CA94304, USA. ${ }^{3}$ Department of Anesthesiolgy, Stanford University School of Medicine, Stanford CA94304, USA.

Received: 16 March 2012 Accepted: 29 June 2012

Published: 23 July 2012

\section{References}

1. Sarangi PP, Ward AJ, Smith EJ, Staddon GE, Atkins RM: Algodystrophy and osteoporosis after tibial fractures. J Bone Joint Surg Br 1993, 75:450-452.

2. Guo TZ, Offley SC, Boyd EA, Jacobs CR, Kingery WS: Substance P signaling contributes to the vascular and nociceptive abnormalities observed in a tibial fracture rat model of complex regional pain syndrome type I. Pain 2004, 108:95-107.

3. Groeneweg JG, Huygen FJ, Heijmans-Antonissen C, Niehof S, Zijlstra FJ: Increased endothelin-1 and diminished nitric oxide levels in blister fluids of patients with intermediate cold type complex regional pain syndrome type 1. BMC Musculoskelet Disord 2006, 7:91.

4. Sabsovich I, Guo TZ, Wei T, Zhao R, Li X, Clark DJ, Geis C, Sommer C, Kingery WS: TNF signaling contributes to the development of nociceptive 
sensitization in a tibia fracture model of complex regional pain syndrome type I. Pain 2008, 137:507-519.

5. Sabsovich I, Wei T, Guo TZ, Zhao R, Shi X, Li X, Yeomans DC, Klyukinov M, Kingery WS, Clark JD: Effect of anti-NGF antibodies in a rat tibia fracture model of complex regional pain syndrome type I. Pain 2008, 138:47-60.

6. Wei T, Sabsovich I, Guo TZ, Shi X, Zhao R, Li W, Geis C, Sommer C, Kingery WS, Clark DJ: Pentoxifylline attenuates nociceptive sensitization and cytokine expression in a tibia fracture rat model of complex regional pain syndrome. Eur J Pain 2009, 13:253-262.

7. Li WW, Sabsovich I, Guo TZ, Zhao R, Kingery WS, Clark JD: The role of enhanced cutaneous IL-1 beta signaling in a rat tibia fracture model of complex regional pain syndrome. Pain 2009, 144:303-313.

8. Li WW, Guo TZ, Li XQ, Kingery WS, Clark JD: Fracture induces keratinocyte activation, proliferation, and expression of pro-nociceptive inflammatory mediators. Pain 2010, 151:843-852.

9. Weber M, Birklein F, Neundorfer B, Schmelz M: Facilitated neurogenic inflammation in complex regional pain syndrome. Pain 2001, 91:251-257.

10. Oyen WJ, Arntz IE, Claessens RM, Van der Meer JW, Corstens FH, Goris RJ: Reflex sympathetic dystrophy of the hand: an excessive inflammatory response? Pain 1993, 55:151-157.

11. Leis S, Weber M, Isselmann A, Schmelz M, Birklein F: Substance-P-induced protein extravasation is bilaterally increased in complex regional pain syndrome. Exp Neurol 2003, 183:197-204.

12. Leis $S$, Weber $M$, Schmelz M, Birklein F: Facilitated neurogenic inflammation in unaffected limbs of patients with complex regional pain syndrome. Neurosci Lett 2004, 359:163-166.

13. Weidner C, Klede M, Rukwied R, Lischetzki G, Neisius U, Skov PS, Petersen LJ, Schmelz M: Acute effects of substance $P$ and calcitonin gene-related peptide in human skin-a microdialysis study. J Invest Dermatol 2000, 115:1015-1020.

14. Wei T, Li WW, Guo TZ, Zhao R, Wang L, Clark DJ, Oaklander AL, Schmelz M, Kingery WS: Post-junctional facilitation of Substance $P$ signaling in a tibia fracture rat model of complex regional pain syndrome type I. Pain 2009, 144:278-286.

15. Guo TZ, Wei T, Kingery WS: Glucocorticoid inhibition of vascular abnormalities in a tibia fracture rat model of complex regional pain syndrome type I. Pain 2006, 121:158-167.

16. Paus $R$, Heinzelmann $T$, Robicsek $S$, Czarnetzki BM, Maurer M: Substance $P$ stimulates murine epidermal keratinocyte proliferation and dermal mast cell degranulation in situ. Arch Dermatol Res 1995, 287:500-502.

17. Tanaka T, Danno K, Ikai K, Imamura S: Effects of substance $P$ and substance $\mathrm{K}$ on the growth of cultured keratinocytes. J Invest Dermatol 1988, 90:399-401.

18. Saade NE, Massaad CA, Ochoa-Chaar Cl, Jabbur SJ, Safieh-Garabedian B, Atweh SF: Upregulation of proinflammatory cytokines and nerve growth factor by intraplantar injection of capsaicin in rats. J Physio/ 2002, 545:241-253.

19. Zimmermann M: Ethical guidelines for investigations of experimental pain in conscious animals. Pain 1983, 16:109-110.

20. Hongo JS, Laramee GR, Urfer R, Shelton DL, Restivo T, Sadick M, Galloway A, Chu $\mathrm{H}$, Winslow JW: Antibody binding regions on human nerve growth factor identified by homolog- and alanine-scanning mutagenesis. Hybridoma 2000, 19:215-227.

21. Halvorson KG, Kubota K, Sevcik MA, Lindsay TH, Sotillo JE, Ghilardi JR, Rosol TJ, Boustany L, Shelton DL, Mantyh PW: A blocking antibody to nerve growth factor attenuates skeletal pain induced by prostate tumor cells growing in bone. Cancer Res 2005, 65:9426-9435.

22. Sevcik MA, Ghilardi JR, Peters CM, Lindsay $T H$, Halvorson KG, Jonas BM, Kubota K, Kuskowski MA, Boustany L, Shelton DL, Mantyh PW: Anti-NGF therapy profoundly reduces bone cancer pain and the accompanying increase in markers of peripheral and central sensitization. Pain 2005, 115:128-141.

23. Shelton DL, Zeller J, Ho WH, Pons J, Rosenthal A: Nerve growth factor mediates hyperalgesia and cachexia in auto-immune arthritis. Pain 2005 116:8-16.

24. Gitter BD, Bruns RF, Howbert JJ, Waters DC, Threlkeld PG, Cox LM, Nixon JA, Lobb KL, Mason NR, Stengel PW, et al: Pharmacological characterization of LY303870: a novel, potent and selective nonpeptide substance $P$ (neurokinin 1) receptor antagonist. J Pharmacol Exp Therapeut 1995, 275:737-744.
25. Hipskind PA, Howbert JJ, Bruns RF, Cho SSY, Crowell TA, Foreman MM, Gehlert DR, lyengar S, Johnson KW, Krushinski JH, Li DL, Lobb KL, Mason NR, Muehl BS, Nixon JA, Phebus LA, Regoli D, Simmons RM, Threlkeld PG, Waters DC, Gitter BD: 3-Aryl-1,2,-diacetamidopropane derivatives as novel and potent NK-1 receptor antagonists. J Med Chem 1996, 39:736-748.

26. lyengar S, Hipskind PA, Gehlert DR, Schober D, Lobb KL, Nixon JA, Helton DR, Kallman MJ, Boucher S, Couture R, Li DL, Simmons RM: LY303870, a centrallyactive neurokinin-1 antagonist with a long duration of action. J Pharmacol Exp Ther 1997, 280:774-785.

27. Kingery WS, Davies MF, Clark JD: A substance $P$ receptor (NK1) antagonist can reverse vascular and nociceptive abnormalities in a rat model of complex regional pain syndrome type II. Pain 2003, 104:75-84.

28. Wojtowicz JM, Kee N: BrdU assay for neurogenesis in rodents. Nat Protoc 2006, 1:1399-1405

29. Schinkel C, Gaertner A, Zaspel J, Zedler S, Faist E, Schuermann M: Inflammatory mediators are altered in the acute phase of posttraumatic complex regional pain syndrome. Clin J Pain 2006, 22:235-239.

30. de Mos M, Huygen FJ, Stricker BH, Dieleman JP, Sturkenboom MC: The association between ACE inhibitors and the complex regional pain syndrome: Suggestions for a neuro-inflammatory pathogenesis of CRPS. Pain 2009, 142:218-224.

31. Kramer HH, He L, Lu B, Birklein F, Sommer C: Increased pain and neurogenic inflammation in mice deficient of neutral endopeptidase. Neurobiol Dis 2009, 35:177-183.

32. Sahbaie P, Shi X, Guo TZ, Qiao Y, Yeomans DC, Kingery WS, Clark JD: Role of substance $P$ signaling in enhanced nociceptive sensitization and local cytokine production after incision. Pain 2009, 145:341-349.

33. Dionne RA, Max MB, Gordon SM, Parada S, Sang C, Gracely RH, Sethna NF, MacLean DB: The substance $P$ receptor antagonist CP-99,994 reduces acute postoperative pain. Clin Pharmacol Ther 1998, 64:562-568.

34. Kingery WS: Role of neuropeptide, cytokine, and growth factor signaling in complex regional pain syndrome. Pain Med 2010, 11:1239-1250

35. Malik-Hall M, Dina OA, Levine JD: Primary afferent nociceptor mechanisms mediating NGF-induced mechanical hyperalgesia. Eur J Neurosci 2005, 21:3387-3394

36. Cattaneo A: Tanezumab, a recombinant humanized $\mathrm{mAb}$ against nerve growth factor for the treatment of acute and chronic pain. Curr Opin Mol Ther 2010, 12:94-106.

37. Lane NE, Schnitzer TJ, Birbara CA, Mokhtarani M, Shelton DL, Smith MD, Brown MT: Tanezumab for the treatment of pain from osteoarthritis of the knee. N Engl J Med 2010, 363:1521-1531.

38. Schnitzer TJ, Lane NE, Birbara C, Smith MD, Simpson SL, Brown MT: Long-term open-label study of tanezumab for moderate to severe osteoarthritic knee pain. Osteoarthr Cartil 2011, 19:639-646.

39. Katz N, Borenstein DG, Birbara C, Bramson C, Nemeth MA, Smith MD, Brown MT: Efficacy and safety of tanezumab in the treatment of chronic low back pain. Pain 2011, 152:2248-2258.

40. Zhao P, Barr TP, Hou Q, Dib-Hajj SD, Black JA, Albrecht PJ, Petersen K, Eisenberg E, Wymer JP, Rice FL, Waxman SG: Voltage-gated sodium channel expression in rat and human epidermal keratinocytes: evidence for a role in pain. Pain 2008, 139:90-105.

41. Hou Q, Barr T, Gee L, Vickers J, Wymer J, Borsani E, Rodella L, Getsios S, Burdo T, Eisenberg E, Guha U, Lavker R, Kessler J, Chittur S, Fiorino D, Rice F, Albrecht P: Keratinocyte expression of calcitonin gene-related peptide beta: implications for neuropathic and inflammatory pain mechanisms. Pain 2011, 152:2036-2051.

42. Urban LA, Fox AJ: NK1 receptor antagonists-are they really without effect in the pain clinic? Trends Pharmacol Sci 2000, 21:462-464. author reply 465.

doi:10.1186/1742-2094-9-181

Cite this article as: Wei et al: Keratinocyte expression of inflammatory mediators plays a crucial role in substance P-induced acute and chronic pain. Journal of Neuroinflammation 2012 9:181. 